\title{
Seminari di storia della lettura e della ricezione, tra Italia e Francia, nel Cinquecento, a cura di Anna Bettoni
}

\section{Filippo Fassina}

\section{(2) OpenEdition \\ Journals}

\section{Edizione digitale}

URL: http://journals.openedition.org/studifrancesi/1309

DOI: 10.4000/studifrancesi.1309

ISSN: 2421-5856

\section{Editore}

Rosenberg \& Sellier

\section{Edizione cartacea}

Data di pubblicazione: 1 décembre 2015

Paginazione: 583-584

ISSN: 0039-2944

\section{Notizia bibliografica digitale}

Filippo Fassina, «Seminari di storia della lettura e della ricezione, tra Italia e Francia, nel Cinquecento, a cura di Anna Bettoni», Studi Francesi [Online], 177 (LIX | III) | 2015, online dal 01 décembre 2015, consultato il 13 janvier 2021. URL: http://journals.openedition.org/studifrancesi/1309 ; DOI: https:// doi.org/10.4000/studifrancesi. 1309

Questo documento è stato generato automaticamente il 13 janvier 2021.

\section{cc) (†) $\odot$}

Studi Francesi è distribuita con Licenza Creative Commons Attribuzione - Non commerciale - Non opere derivate 4.0 Internazionale. 


\title{
Seminari di storia della lettura e della ricezione, tra Italia e Francia, nel Cinquecento, a cura di Anna Bettoni
}

\author{
Filippo Fassina
}

\section{NOTIZIA}

Seminari di storia della lettura e della ricezione, tra Italia e Francia, nel Cinquecento, vol. 3, a cura di Anna BETTONI, Padova, CLEUP, 2014, pp. 136.

1 Il terzo volume dei Seminari di storia della lettura e della ricezione, tra Italia e Francia, nel Cinquecento, che da diversi anni si svolgono all'Università di Padova, sotto la direzione di Anna Bettoni, prosegue il percorso, già avviato nelle precedenti pubblicazioni, di analisi della circolazione dei libri e della cultura nell'Europa del Cinquecento. Filo conduttore, nello specifico, di questo volume, costituito da quattro contributi, è la concretezza e la materialità, intese sia dal punto di vista della pura corporeità, sia come esperienze di vita reale riflesse nel discorso letterario: «la littérature n'a jamais été un espace autonome, séparé du vivant et du matériel, coupé de la chair et des soubresauts. Aujourd'hui comme à la Renaissance, elle se nourrit du réel, s'en imprègne pour le comprendre, le questionner, le repenser, parfois le transcender» (p. 51).

2 Si parte da Rabelais, con l'intervento di Nadine KUPERTY-TSUR (Genre, sexe et construction du savoir dans le chapitre XV de Pantagruel, pp. 29-50), che offre un'interpretazione originale su un capitolo tra i più complessi dell'opera rabelaisiana, capitolo che, a livello di struttura superficiale, appare incoerente, ma che, in realtà è ricco di rimandi e di riferimenti interni. La struttura quadripartita, che parte da un dialogo tra Pantagruel e Panurge, prosegue con un conte animalier e con una farce e si chiude con una riscrittura di una favola di Esopo, viene ricondotta a un'unica matrice, analizzando gli elementi comuni e identificando le analogie che legano i vari generi letterari che costituiscono il XV capitolo. Le murailles di Parigi, che, a detta dei protagonisti, 
dovrebbero essere costituite dai sessi femminili, trovano una corrispondenza nel racconto del leone e della volpe, che scambiano l'organo genitale femminile con una ferita e tentano di curarla. Allo stesso modo, l'aneddoto che chiude il capitolo, in cui un padre discute sulla verginità delle sue due piccole figlie, riprende, estremizzandolo, il tema della sessualità femminile. Lungi dall'essere un giudizio misogino, l'intero capitolo è interpretato in questo saggio come una riflessione sul ruolo della donna e sul rapporto che l'uomo ha nei confronti dei due sessi.

3 Il contributo di Loris PETRIS (Entre poésie et «realia»: Joachim Du Bellay, lecteur de Jean Du Bellay, pp. 51-84) ha la finalità di confrontare le opere di Joachim du Bellay con quelle del suo mentore, Jean du Bellay (soprattuto per ciò che concerne l'epistolario, ormai interamente edito), per rilevarne il contesto storico e i realia che sottostanno alle due opere. Vengono forniti numerosi esempi di come l'esperienza di vita del cardinale Jean influenzi le opere di Joachim, risultando una vera e propria fonte di ispirazione. Sono considerati, in questo intervento, alcuni degli elementi e degli eventi più importanti della vita del cardinale, che Joachim riprende e sviluppa dal punto di vista letterario e poetico. In primo luogo, l'opposizione tra vocazione poetica e obblighi professionali (opposizione tra otium e negotium, peraltro, di matrice oraziana), che è ampiamente discussa nei testi di Jean. Inoltre, viene descritta la biblioteca personale di Jean Du Bellay, che costituiva una miniera di testi e di informazioni alle quali Joachim poteva accedere: purtroppo non ne possediamo un inventario completo, ma una parte di questi testi è stata ricostruita a partire dagli ex libris. Ampio spazio in questo contributo è dato al fatto cruciale nella vita del cardinale Du Bellay: la permanenza, a partire dal 1555, a Roma, vissuta come un vero e proprio esilio. Questa tematica (anch'essa di matrice classica, con la figura dominante di Ovidio) diventa topos anche nelle opere di Joachim, soprattutto per quanto concerne i rapporti tra necessità finanziarie e mélancolie. Infine, è persistente nei testi di entrambi gli eruditi il tema delle ruines e delle antiquités, che diventano vero e proprio simbolo di quella concretezza che, a livello letterario, si configura come immagine del mondo interiore. È proprio questo legame, fra letteratura e realia, che crea un movimento testo-contesto, tale da permettere di vedere sotto una luce nuova molti riferimenti testuali, che senza questa chiave di lettura, resterebbero incomprensibili.

Claude Expilly e il suo rapporto con il milieu culturale italiano sono invece oggetto di studio del lavoro di Alessandra PREDA (Scrivere tra i versi altrui: la lezione italiana nell'opera di Claude Expilly, pp. 85-102), che ripercorre il viaggio in Italia (Torino, Padova e Venezia) con il quale l'umanista completa il suo iter di giureconsulto. Soprattutto i suoi contatti con i salotti eruditi padovani saranno fondamentali per la genesi delle sue opere, in particolare per i suoi canzonieri. Modello importantissimo è, senza dubbio, Sperone Speroni, che introduce Expilly nella prestigiosissima biblioteca di Gian Vincenzo Pinelli. Anche il mercato librario veneziano offre all'erudito francese una quantità enorme di testi che andranno a comporre la sua corposa biblioteca. Proprio a Venezia si avvicina al modello di Petrarca e dei petrarchisti italiani, di cui acquista i testi, e li commenta attraverso una serie di note autografe interessantissime per lo studioso moderno. Tutto questo materiale confluirà, infatti, nell'edizione dei 1596 dei Poëmes, che è una rielaborazione delle tematiche petrarchesche, contaminate anche da un altro modello, Tasso, emulato soprattutto per le sue raffinatezze stilistiche. Altro modello fondamentale per Expilly sono gli Essais di Montaigne, nei quali egli ritrova l'ideale di intellettuale saggio e stoico, in grado di resistere alla temperie dell'epoca. Con la maturità, tuttavia, è ancora il modello di Petrarca che influenza la poetica di 
Expilly: questa volta non più il Petrarca sentimentale della lirica amorosa, ma l'uomo delle meditazioni filosofiche sui temi dell'errore, della morte e dell'eterno, più attinenti alla consapevolezza esistenziale della vecchiaia.

5 Il rapporto fra letteratura francese e letteratura italiana è centrale anche nell'ultimo contributo di questo volume, quello di Laura RESCIA (Metamorfosi di un eroe cavalleresco: Rodomonte sulle scene francesi di primo Seicento, pp.103-118). Viene, infatti, preso in esame un testo del 1605, la Rodomontade di Charles Bauter, che narra, sotto forma di tragicommedia, la discesa agli inferi di Rodomonte, personaggio dell'Orlando Furioso, abbandonato al suo destino di morte da Ariosto. La fortuna ariostesca in Francia tra la fine del Cinquecento e l'inizio del Seicento è manifesta, anche se l'utilizzo di un genere letterario come quello sperimentato da Bauter è, senza dubbio, meno frequente. In questo studio viene in primo luogo dimostrato che la Rodomontade ebbe una larga diffusione e fu quasi sicuramente rappresentata. Dal punto di vista intertestuale, viene citato Charles Sorel, che nella sua raccolta di novelle La Maison des jeux (1657) parla proprio della rappresentazione scenica di una discesa agli inferi di Rodomonte abbinata a una forma espressiva irregolare; inoltre, attraverso una minuziosa analisi bibliologica e filologica delle variationes del testo, si ipotizza che vi furono svariate edizioni pirata derivate dalla trascrizione di una rappresentazione teatrale di successo. Vengono poi evidenziati i debiti della pièce nei confronti di altri testi francesi e italiani: la Bradamante di Robert Garnier (1582), una delle prime tragicommedie francesi, La Mort de Rodomont di Philippe Desportes (1572) e la Marfisa di Pietro Aretino. Di queste opere vengono forniti numerosi esempi di intertestualità. Infine, viene analizzata la struttura della Rodomontade, mettendo in luce una caratteristica interessantissima e peculiare: per ogni atto viene, infatti, applicato un sottogenere: nel primo atto la tragicommedia, nel secondo la tragedia, nel terzo e nel quarto la commedia burlesca, e ancora la tragedia nel quinto atto. Si può dire dunque che «la pièce restituisca una visione arcimboldesca di una materia letteraria, quella ariostesca, probabilmente già ben conosciuta al pubblico dell'epoca» (p. 115).

6 Nel complesso, il presente volume offre un percorso coerente e brillante sul rapporto tra testo e materialità, collegando tra loro i singoli contribuiti, grazie al fil rouge dei rapporti di intertestualità e di imitatio, in un periodo in cui il testo è vivo e si arricchisce continuamente di nuovi elementi, a volte anche indipendentemente dall'autore stesso che l'ha creato. 